\title{
Schizophrenia and the structure of language: The linguist's view
}

\author{
Michael A. Covington ${ }^{\mathrm{a}, *}$, Congzhou $\mathrm{He}^{\mathrm{a}}$, Cati Brown ${ }^{\mathrm{a}}$, Lorina Naçi ${ }^{\mathrm{a}, 1}$, \\ Jonathan T. McClain ${ }^{\mathrm{a}, 2}$, Bess Sirmon Fjordbak ${ }^{\mathrm{a}}$, James Semple ${ }^{\mathrm{b}, \mathrm{c}}$, John Brown ${ }^{\mathrm{b}}$ \\ ${ }^{a}$ Artificial Intelligence Center, The University of Georgia, 111 Boyd GSRC, Athens, GA 30602-7415, USA \\ ${ }^{\mathrm{b}}$ GlaxoSmithKline Research and Development Ltd., Addenbrooke's Hospital, Cambridge CB2 2GG, UK \\ ${ }^{\mathrm{c}}$ Department of Psychiatry, Cambridge University, Addenbrooke's Hospital, Cambridge CB2 2QQ, UK
}

Received 10 December 2004; received in revised form 21 January 2005; accepted 26 January 2005 Available online 2 April 2005

\begin{abstract}
Patients with schizophrenia often display unusual language impairments. This is a wide ranging critical review of the literature on language in schizophrenia since the 19th century. We survey schizophrenic language level by level, from phonetics through phonology, morphology, syntax, semantics, and pragmatics.

There are at least two kinds of impairment (perhaps not fully distinct): thought disorder, or failure to maintain a discourse plan, and schizophasia, comprising various dysphasia-like impairments such as clanging, neologism, and unintelligible utterances.

Thought disorder appears to be primarily a disruption of executive function and pragmatics, perhaps with impairment of the syntax-semantics interface; schizophasia involves disruption at other levels. Phonetics is also often abnormal (manifesting as flat intonation or unusual voice quality), but phonological structure, morphology, and syntax are normal or nearly so (some syntactic impairments have been demonstrated). Access to the lexicon is clearly impaired, manifesting as stilted speech, word approximation, and neologism. Clanging (glossomania) is straightforwardly explainable as distraction by self-monitoring.

Recent research has begun to relate schizophrenia, which is partly genetic, to the genetic endowment that makes human language possible.

(C) 2005 Elsevier B.V. All rights reserved.

Keywords: Speech; Language; Schizophasia; Thought disorder; Semantics; Pragmatics

\footnotetext{
This research was funded by GlaxoSmithKline Research \& Development Ltd. as part of the project CASPR (Computer Analysis of Speech for Psychiatric Research), Michael A. Covington, principal investigator. We thank Willem J. Riedel of GlaxoSmithKline for helpful discussions.

* Corresponding author. Tel.: +1 706542 0358; fax: +1 7065428864 .

E-mail address: mc@uga.edu (M.A. Covington).

${ }^{1}$ Now at Department of Experimental Psychology, Cambridge University, Cambridge CB2 3EB, UK.

${ }^{2}$ Now at Sandia National Laboratories, P.O. Box 5800, Albuquerque, NM 87185-1188, USA.
} 


\section{Introduction}

Many, though not all, patients diagnosed with schizophrenia display abnormalities of language. These abnormalities are highly variable and often hard to characterize. It is often unclear whether they reflect deficits in language itself or in related cognitive processes such as planning, execution, and memory.

In this paper, we review schizophrenic language impairments from the linguist's viewpoint, to see how schizophrenia affects phonology, syntax, semantics, and other recognized components of language. Our goal is to identify the important observed phenomena and important ideas about them.

The research publications reviewed here were found partly by computer search and partly by reading broadly and following up references, with special attention to older sources not retrievable by computer search. Other useful literature reviews, less linguistically oriented than our own, have been given by Andreasen (1979a,b), Cutting (1985), Chaika (1990), McGrath (1991) McKenna (1994), Rieber and Vetter (1994), Thomas and Fraser (1994), and DeLisi (2001).

\section{Language disorder and thought disorder}

\subsection{Formal thought disorder}

In the psychiatric literature, many of the abnormalities of language in schizophrenia are lumped together as formal thought disorder (a disorder in the form of thought, not the content). McKenna (1994, pp. 10-11) explains:

The term undoubtedly encompasses a number of quite disparate abnormalities. ... Perhaps most commonly it is the moment-to-moment, logical sequencing of ideas which is at fault. At other times, the mechanisms of language production themselves appear to be disturbed, so that the meaning of individual words and phrases is obscured. At still other times, the fault seems to be at the level of discourse: individual words, sentences, and sequences of thought make sense, but there is no discernible thread to longer verbal productions.
Florid formal thought disorder is "a relatively uncommon finding in acute schizophrenia" (McKenna, 1994, p. 12), though it is somewhat more common in chronic cases.

Manifestations of formal thought disorder include poverty of content (failure to express sufficient information), loss of goal (slippage away from the intended topic), clanging (chaining together similarsounding words as if distracted by them), and other kinds of incoherence and unintelligibility.

\subsection{Chaika on linguistic structure}

The study of schizophrenic language disorder by linguists began with Chaika (1974), who studied a single patient who "spoke normally for weeks at a time, her deviant language coinciding with what her psychiatrists term 'psychotic episodes"'(p. 259). Stripped of some mid-1970s theoretical terminology, and condensed somewhat, the abnormalities that Chaika observed were:

(1) Failure to utter the intended lexical item;

(2) Distraction by the sounds or senses of words, so that a discourse becomes a string of word associations rather than a presentation of previously intended information;

(3) Breakdown of syntax and/or discourse;

(4) Lack of awareness that the utterances are abnormal.

Of these, (2) is most characteristic of schizophrenia; (1) and (3) resemble ordinary speech errors, and (4) resembles some forms of aphasia.

\subsection{Schizophrenic language vs. normal speech errors}

Fromkin (1975) responded that "except for the disruption of. . .discourse which can be attributed to non-linguistic factors, all the features [of schizophrenic language] are prevalent in normal speech as exemplified by speech errors and "slips of the tongue" Mistaken lexical choices and minor scramblings of syntax are common in everyday speech. Indeed, speech errors are often triggered by the sounds or senses of recently uttered words, and speakers are commonly unaware of their fumbles (Fromkin (1973); Meringer and Mayer (1895); Freud (1904/1965)). 
Thus, (1), (2), (3), and (4) of Chaika's core abnormalities are all disposed of, except for derailment of discourse, which Fromkin considers extralinguistic.

This claim has not held up. Although there are obvious similarities between Chaika's samples of schizophrenic language and Fromkin's corpus of speech errors, there are also obvious differences. Normal speakers make occasional errors like those seen in schizophrenia, but not whole strings of errors. A representative patch of gibberish from Chaika's patient comprised 9 syllables, and uncorrected speech errors of such length and unintelligibility do not occur in normal speech. What's more, normal speakers, when an error is pointed out, immediately correct it; speakers with schizophrenia do not.

Moreover, Chaika's patient would commonly string together 10 or 20 sentences connected, as far as one can see, only by word associations (Chaika, 1974, pp. 260-261); ordinary people, even when plagued by speech errors, do not do this. Normal speech errors are momentary deviations from a discourse plan that is immediately resumed.

\subsection{Loss of voluntary control}

In later work, Chaika (1990) argues that schizophrenic language disorder is fundamentally a loss of voluntary control over the speech generation process. Indeed, according to Chapman (1966), patients sometimes say in retrospect that this is exactly what happened - they couldn't control their speech. This echoes the main theme of the Schneiderian first-rank symptoms (Schneider, 1959, Mellor, 1970), which is loss of control over the train of thought. Note however that Chaika's original patient (1974) apparently lacked such insight.

Chaika argues that loss of voluntary control ties together a wide range of observed phenomena, depending on which part of language production goes out of control - most often discourse organization, but often lexical retrieval, and sometimes pronunciation or syntax. It fits well into a more general conception of schizophrenia as degradation of communication between mental subsystems. ${ }^{3}$

\footnotetext{
${ }^{3}$ Not necessarily physical areas of the brain, but modules of the mental software.
}

\subsection{Schizophrenic language disorders vs. aphasia}

How much do the language disturbances of schizophrenia resemble the aphasia caused by stroke, traumatic brain injury, or neurological conditions such as epilepsy? ${ }^{4}$

Researchers agree that there are important differences, but beyond that, discussion of the issue has been complicated by the heterogeneity of both schizophrenia and aphasia. Lecours and VanierClément (1976) claim that:

- Aphasia-like symptoms are "episodically observed in only a small proportion of subjects considered to be schizophrenics" (p. 516) whereas the aphasia produced by stroke or brain injury is in most cases constantly present.

- Patients with aphasia have normal thoughts and express them with difficulty; those with schizophrenia have unusual thoughts (or disorganized discourse plans) and express them with comparative ease.

The latter of these is more a programmatic definition than an empirical observation, since it begs the question of whether the patient could evince unusual thoughts without language.

Pinard and Lecours (1983) compare schizophrenic language to Wernicke's aphasia (including jargon aphasia), a disorder in which the patient speaks fluently but unintelligibly. Their main findings:

- Schizophasic discourse often has a preferred theme or preoccupation; aphasic discourse rarely does.

- Speakers with schizophrenia often jump from one subject to another based on the sounds or associations of words they have uttered (association chaining or glossomania). "This... is seldom observed in jargon aphasia; it requires lexical mastery well beyond that of most aphasics, as well as remarkable control of prosody" (p. 320).

- Schizophasic discourse often includes rare words, evidence of a large, intact vocabulary; jargon aphasia, even when very fluent, shows a restricted vocabulary.

\footnotetext{
${ }^{4}$ Throughout, following the usage of the sources cited, we understand "aphasia" to include dysphasia (partial impairment).
} 
- Schizophrenic speech can include conscious creation of new words (neologisms) and consciously constrained discourse in which the speaker is well aware that the speech is unusual, whether or not others can understand it. Aphasic speakers who produce fluent unintelligible discourse do not seem to be fully aware of what they are doing, and if they create new words, it is as if by accident.

Based on clinical experience, Taylor (1999, pp. 64-68) finds somewhat more overlap between formal thought disorder and aphasia, especially posterior (Wernicke's) aphasia. He distinguishes them largely by verbal comprehension, which is relatively intact in schizophrenia. Gerson et al. (1977) give a different set of distinguishing criteria revolving around the claim that patients with aphasia have more insight than those with schizophrenia into the fact that communication is failing (more or less the direct opposite of Pinard and Lecours (1983)'s perspective). Finally, Oh et al. (2002) report that standard aphasia tests do not detect formal thought disorder. They conclude that thought disorder is distinct from the widely recognized forms of aphasia.

\subsection{Andreasen's 18-point scale}

The standard account of schizophrenic language today is that of Andreasen (1979a,b), whose Thought, Language, and Communication (TLC) scale (Andreasen, 1986) (later refined as Andreasen and Grove, 1986) provided a foundation for subsequent research and clinical practice.

The scale comprises 18 symptoms: poverty of speech, poverty of content (wordy vagueness), pressure of speech (excessive speed or emphasis), distractibility (by stimuli in the environment), tangentiality (partly irrelevant replies), loss of goal, derailment (loss of goal in gradual steps), circumstantiality (numerous digressions on the way to the goal), illogicality, incoherence ("word salad," severely disrupted structure), neologisms (novel made-up words), word approximations (coined substitutes for existing words, such as handshoe 'glove'), stilted speech (pompous or overly formal style), clanging, perseveration, echolalia, blocking (sudden stoppage), and self-reference (talking about oneself excessively). (We have reordered Andrea- sen's list to put similar symptoms together. On the arrangement of these dysfunctions into linguistic levels see also Thomas (1997).)

Formal thought disorder is certainly not confined to schizophrenia. Clanging, in Andreasen's sample, occurred in mania but not in schizophrenia, even though it is normally considered typically schizophrenic. Many of the "negative" speech symptoms (poverty of speech, derailment, loss of goal, and blocking) also occurred in depression. Based on these results, Andreasen argues cogently that the symptoms comprise a range of distinct dysfunctions with no simple common core.

\subsection{Which symptoms are the most common?}

Whereas Chaika's work was based on a few unusually florid cases, Andreasen (1979b)'s study gives some statistical perspective. She reports that in 45 patients diagnosed with schizophrenia:

- derailment, loss of goal, poverty of content, and tangentiality were the most common of the 18 thought-disorder symptoms;

- poverty of speech, pressure of speech, illogicality, and perseveration were moderately common;

- self-reference and incoherence were moderately uncommon;

- and the remaining thought-disorder symptoms were rare.

A much larger sample would of course be required for entirely valid statistics.

\subsection{Which symptoms correlate with which?}

\subsubsection{Andreasen's subgrouping}

Andreasen's first attempt at a factor analysis (Andreasen, 1979b) yielded only one definite factor, "verbosity," which is low in poverty of speech, and high in derailment, illogicality, loss of goal, perseveration, incoherence, and pressure of speech. "Loose associations" (tangentiality, derailment, incoherence, illogicality, and clanging) formed a separate group apparently orthogonal to "verbosity."

A later study (Andreasen and Grove, 1986) found two main factors, "fluent disorganization" (pressure, distractibility, derailment, loss of goal, and persever- 
ation) versus "emptiness" (poverty of speech and content), characteristic of mania and schizophrenia respectively.

\subsubsection{Liddle's $T L I$}

Liddle et al. (2002) simplified Andreasen's TLC index into a Thought and Language Index comprising 8 symptoms, which factor analysis divided into 3 groups (Table 1) with strong, cleanly separate factor loadings.

They found that the disorganization and impoverishment symptom groups were "approximately orthogonal rather than bipolar" (neither one is the opposite of the other; they can coexist in any combination). Perseveration and distractibility correlated with each other but were independent of both impoverishment and disorganization.

Another noteworthy result was that "the scores in the healthy control group were not negligible," i.e., the abnormalities were found, in mild form, in non-patients.

The triad of Liddle et al. (2002) resembles other classifications of symptoms of schizophrenia going back all the way to the 19th-century division into catatonia (negative symptoms), paranoia (odd thoughts), and hebephrenia (disorganization).

\subsubsection{Chen's CLANG}

In a paper that deserves to be better known, Chen et al. (1996) present an alternative to Andreasen's TLC scale and its derivatives. Their CLANG (Clinical Language) scale comprises 17 symptoms classified according to levels of linguistic structure. ${ }^{5}$ Ranging beyond Andreasen's and Liddle's scales, CLANG includes disturbances of fluency, voice quality, and articulation. It is a fuller evaluation of speech, not just "thought" or discourse.

The factor analysis by Chen et al. found three major kinds of language dysfunction in schizophrenic patients, "syntactic," "semantic," and "production." "Syntactic" dysfunction affects the structure of language on all levels, including lexical access. "Semantic" dysfunction affects the ability to map thoughts onto language and pursue a communicative goal; it corresponds closely to the traditional definition of thought disorder. "Production" dysfunction

\footnotetext{
5 The name CLANG is a pun; the scale is of course not a measure of clanging.
}

Table 1

Components of the Thought and Language Index (TLI) of Liddle et al. (2002)

\begin{tabular}{ll}
\hline Impoverishment & $\begin{array}{l}\text { Poverty of speech } \\
\text { Weakening of goal }\end{array}$ \\
Disorganization & $\begin{array}{l}\text { Looseness (derailment, tangentiality) } \\
\text { Peculiar words (rare or neologized) } \\
\text { Peculiar sentences (odd syntax) } \\
\text { Peculiar logic (non-logical reasoning) }\end{array}$ \\
& Perseveration (repetition of ideas) \\
Dysregulation & Distractibility (by external stimuli) \\
\hline
\end{tabular}

comprises poverty of speech, lack of details, and lack of intonation; it is associated with the negative symptoms of schizophrenia.

There are also factors for "pressure" and "prosody" (each cleanly self-contained, even though "prosody" is only one symptom) and two symptoms, dysarthria and excessive details, that are unclassified because they have minor loadings in several factors.

Ceccherini-Nelli and Crow (2003) got a different factor analysis in which the "syntactic" and "semantic" factors fell together into one, perhaps because of different scoring criteria. Their second factor, "poverty," corresponds closely to the "production" of Chen et al. Their third factor, "excess," comprises syntactic perseveration ("excess syntactic constraints") and excessive detail (interpretable as semantic perseveration).

\section{Linguistic levels}

\subsection{Stratification of language}

Since ancient times, grammarians have noticed that human language has a multi-level structure. The facts that describe any language tend to cluster into levels that make little reference to each other. Most of the phonology of any language can be described without any reference to its syntax, and vice versa. The levels interact largely through the lexicon (vocabulary), which tells us, for instance, that the sound sequence /mæn/ (phonology) forms the word man, which is the singular of men (morphology), a noun (syntax) that signifies a male human being (semantics) and is relatively unrestricted as to style and connotations (pragmatics). 
In what follows, we review the literature on schizophrenic language abnormalities, level by level.

\subsection{Phonetics and phonology}

\subsubsection{Segmental phonology}

According to all reports, segmental phonology in schizophrenia is obstinately normal. Even the most unintelligible utterances conform to the arrangements of speech sounds permitted in the patient's language. "In fact, because they are so consistent with the stress and phonemic rules of English, one thinks the patient has actually made utterances of the language which one has failed to catch" (Chaika, 1974, p. 261). Chaika is describing utterances which she presents both in phonetic transcription and in ordinary English spelling; they include the sawendon saw turch faw jueri and fooch with teykrimez. Compare Lecours and Vanier-Clément (1976) and Cutting (1985), who make similar points about wider sets of data.

\subsubsection{Prosody (timing and intonation)}

Flattened intonation (aprosody) is an often-noted negative symptom of schizophrenia. Cutting (1985, p. 254) cites a number of studies showing that not only the production but also the comprehension of intonation contours (as an expression of emotion) is impaired. Other studies of aprosody are reviewed by Rieber and Vetter (1994, pp. 174-177) and Alpert et al. (1989). Classic work on the acoustics of emotion was done by Williams and Stevens (1972).

Spoerri (1966) cites with approval an observation by C. Cherry that even when not demonstrably aprosodic, patients with schizophrenia often sound like a person talking on the telephone (in a day when telephones were less familiar and had poorer sound quality than today): the intonation and loudness are more constant, as if the hearer's response were not available for the speaker to adjust to it.

Schizophrenic speech contains more pauses and hesitations than normal speech. Clemmer (1980) found that these characteristics of schizophrenic speech can be replicated in healthy volunteers by having them read or retell stories into which a completely extraneous, unrelated event has been inserted. Thus, the pauses of the schizophrenic may be at least partly the result of difficulties at the semantic or pragmatic level, rather than a specifically phonological impairment.

\subsubsection{Voice quality}

Spoerri did pioneering work on both prosody and voice quality in schizophrenia (Spoerri, 1961, 1964,1966). He reports that catatonia is associated with a voice quality called Gepresstheit 'strained quality' or Würgstimme 'choking voice' perhaps an extreme form of what English-speaking phoneticians call creaky voice.

Analyzing speech musicologically, Stein (1993) found detectable abnormalities of pitch in almost all of the schizophrenics studied, but relatively few patients diagnosed with mania or reactive psychosis. She argues that flat intonation does not reflect absence of emotion: "those in the present study complained of an inability to express affect, but not an absence of affect" (p. 61). Speaking in a soft monotone requires great effort; narrowed pitch and constricted timbre are "negative symptoms that require hard work" (ibid.). Spoerri's work, already mentioned, fills in abundant phonetic details with basically the same implication.

Stassen et al. (1995), Püschel et al. (1998), and their colleagues in Zürich have correlated acoustic properties of speech with schizophrenic symptoms. The analyses are statistical and do not probe deeply into the nature of the speech abnormalities. Other papers on psychiatric aspects of voice quality are cited by Stassen (1991).

\subsection{Morphology}

Abnormal morphology in schizophrenia is quite rare. Chaika (1990, p. 92) cites one patient:

I am being help[ed] with the food and the medicate... You have to be able to memory the process...

These could equally well be disruptions of syntax (wrong part of speech) or lexical retrieval (using words that are semantically right but syntactically off-target). Kleist (1914) describes a patient who built a whole series of compounds on German Gefäss 'vessel', such as Zeitgefäss 'time-vessel'=''watch or clock'. Kleist also describes patients who overused the adjective-forming suffixes -artig and $-e t^{6}$

\footnotetext{
${ }^{6}$ Dialectal German for -ig, the adjective-forming suffix.
} 


\subsection{Syntax}

\subsubsection{Normal structure}

The syntax of schizophrenic speech is generally normal, even when the semantics and discourse organization have completely broken down. Even "word salad" is made of normal syntactic components:

If we need soap when you can jump into a pool of water, and then when you go to buy your gasoline, my folks always thought they should get pop, but the best thing is to get motor oil... (Andreasen, 1979a)

This is a wild series of changes of topic, but there is nothing ungrammatical about it, bearing in mind that people need not speak in complete sentences.

\subsubsection{Simplification}

Morice and Ingram (1982), Morice and McNicol (1985), and Morice and McNicol (1986) have demonstrated that schizophrenia is accompanied by a reduction in syntactic complexity and an impairment in syntactic comprehension. These results were replicated by Fraser et al. (1986).

By itself, syntactic simplification need not indicate syntactic impairment. It could result from an overall cognitive deficit, difficulty concentrating, distraction, or a preference for expressing simpler ideas.

Thomas et al. $(1987,1990)$ found greater syntactic simplification in patients with negative symptoms than in those with positive symptoms. The same research group further found that syntactic complexity diminishes as the chronic patient's condition deteriorates (Thomas et al. (1990), King et al. (1990)). The syntactic impairment in schizophrenia appears to be a chronic degenerative symptom relatively unresponsive to treatment. This is not true of semantic deviance in schizophrenia, which tend to resolve at least partially with time, perhaps because it is masked by advancing impairment of another kind.

Levy (1966) found that syntactic complexity rose above pretreatment levels when patients diagnosed with acute schizophrenia were successfully treated with chlorpromazine. Thus, even if chronically degenerative, syntactic impairment is treatable in the short term.

\subsubsection{The price of language?}

DeLisi (2001) was the first to note that syntactic simplification in schizophrenia is relevant to theories of the evolution of language Crow (1997a,b), (2000). Crow's hypothesis is that schizophrenia is "the price Homo sapiens pays for language." That is, the part of our genetic endowment that makes language possible is new and failure-prone, but so valuable that even with its failures (often manifesting as schizophrenia), it is preserved in the gene pool.

DeLisi demonstrated by literature review that language impairment in schizophrenia is pervasive. She then conducted an experiment based on five distinctive properties of human language enumerated by Bickerton (1990, pp. 122-126). Of the five, only phrasal complexity (measured through total amount of speech, clause conjunction, and clause embedding) was reduced in schizophrenia, and this reduction was familial and cosegregated with schizophrenia (it tended not to afflict non-schizophrenic members of the families).

This ties together the genetics of language and the genetics of schizophrenia in an important way, although since only one of Bickerton's five properties was found to be impaired, DeLisi's result arguably favors the picture of evolution of language painted by Pinker (1992) rather than Bickerton's or Crow's hypotheses.

\subsection{Semantics}

Oh et al. (2002) characterize formal thought disorder as "expressive semantic abnormality which, however, spares naming." As they note, the idea of such an abnormality goes back to Head (1926), though he does not report an entirely clear case of it. Head used the term semantic aphasia for disorders in which naming was spared but structural semantics was severely impaired. In the cases that he reported, the impairment extended to syntax, discourse planning, other goal-directed activities, and integration of perceptions in context. This combination is, of course, not wildly different from schizophrenia.

In related work, Rodriguez-Ferrera et al. (2001) examine the language impairment in thought-disordered schizophrenics whose general intellectual ability is preserved. Using language tests, they find "a 
pattern of relatively preserved syntax combined with more obviously impaired semantics, especially higher-order semantics" (p. 203). By higher-order semantics they mean the organization of individual propositions into larger structures (scripts and frames - the plot of a narrative or the logic flow of an exposition).

Very florid impairments are sometimes reported. When a patient with schizophrenia says something like:

Oh, it [life in a hospital] was superb, you know, the trains broke, and the pond fell in the front doorway.

(Oh et al., 2002, p. 235)

do the words mean anything at all? Is the patient actually expressing a thought of a pond falling in the front doorway?

Perhaps not. Not only words, but even thoughts are semantic. That is, they encode concepts and can refer to real-world objects. There are also semantic relations between objects in the real world: smoke is a sign of fire, a picture is a sign of what it depicts, and modern society uses many arbitrary non-verbal symbols. It has been suggested that schizophrenia is fundamentally a semiotic disorder, a disorder of the recognition and use of sign relations (word-to-object, thought-toobject, and object-to-object).

This possibility is pursued at length by Wróbel (1990), who points out that the first symptom of schizophrenia is often a sense that everything in one's environment is filled with special meaning. This proceeds to delusions of reference and a breakdown of communication. See also Harrod (1986), Chaika and Lambe (1986), and Harrow et al. (1986).

\subsection{Pragmatics}

\subsubsection{Pragmatics defined}

Pragmatics, the relationship between language and context, is the level most obviously disordered in schizophrenia: even when their pronunciation and grammar are perfectly normal, people with schizophrenia say strange things at strange times.

Pragmatics as an area of linguistics dates only from the 1970s, and we caution readers that pragmatic phenomena were lumped with semantics, or simply ignored, in earlier literature.

\subsubsection{Cohesion and reference}

Cohesion is the joining of a series of utterances through explicit words and sentence structures, such as pronouns, conjunctions, ellipsis, repetition, use of similar words, and the like. A large part of cohesion deals with establishing reference, i.e., identifying the real-world objects that the speaker is talking about, and keeping the reference clear without excessive repetition of words.

In a seminal work, Rochester and Martin (1979) determined that cohesion is impaired in schizophrenia whether or not overt thought disorder is present:

- Both thought-disordered and non-thought-disordered patients with schizophrenia have a greater tendency to identify referents non-verbally (e.g., by pointing) compared to healthy controls.

- Patients with both types of schizophrenia have trouble with presumed information and indirect references. Normal speakers use presumption and indirect reference without confusing the hearer. Those with non-thought-disordered schizophrenia shy away from using them, as if they are not confident that they can predict what the hearer will understand. Those with thought-disordered schizophrenia often make obscure indirect references and presume information that has not been presented.

- Compared to healthy controls, the use of lexical cohesion is reduced in non-thought-disordered schizophrenia (where the speaker seems to be keeping things simple on purpose) but increased in thought-disordered schizophrenia, where many of the words refer to categories to which individual objects belong.

Subsequent studies of cohesion in schizophrenia have been numerous. Docherty et al. (1996) finds disturbances of cohesion to be common in both schizophrenia and mania, but in different proportions. Structural unclarities and wrong words were especially common in schizophrenia; ambiguous words were especially common in mania. Docherty et al. (2003) found that, in schizophrenia, many of these disturbances (all except vague reference) are "traitlike," stable over time, and relatively uncorrelated with formal thought disorder or severity of psychotic symptoms. This is particularly intriguing because poor cohesion in speech has been thought to 
be a prodromal or subclinical symptom in those with a genetic predisposition to schizophrenia (Wynne et al. (1977), Goldstein (1985), Docherty (1995)).

Much earlier, Hoffman et al. (1985) noticed that pronoun reference was error-prone in the speech of patients diagnosed with schizophrenia. Abu-Akel (1997, 1998) found that treatment with clozapine can improve the cohesion of schizophrenic patients' speech.

\subsubsection{Coherence (connectedness)}

Schizophrenic speech is often described as "incoherent," meaning that it does not hold together. Deese (1978 and 1984) provides an exact way to characterize the coherence of expository discourse. The text or speech sample is broken into propositions or statements which are arranged into a tree diagram. Links in the tree mean not merely that the statements are related, but that the lower statement is dependent on the truth of the upper one to which it is linked.

Using a sentence-by-sentence version of Deese's trees, Hoffman et al. (1986) found impaired coherence in both mania and schizophrenia, but the specific impairments were different. In general, patients with mania seemed to be juggling more than one discourse plan at once, resulting in sudden jumps between elaborate structures. Those with schizophrenia, however, showed an overall lack of structure, and different human scorers tended to analyze the same speech samples differently. This is convincing evidence that, in schizophrenia, discourse planning is impaired.

Nöth (1976) cites interesting examples of incoherent speech (in English) and gives a quantitative scheme for rating them.

\subsubsection{Grice's maxims and implicature}

Talking is a cooperative human activity. Grice (1975) identified a set of "maxims" which people follow in order to communicate cooperatively, such as "Give adequate information, but not too much," and "Be truthful." More than any other area of pragmatics, Grice's maxims involve extralinguistic conscious thinking, and particularly "theory of mind," which is claimed to be deeply disordered in schizophrenia (Frith (1992), Abu-Akel (1999)).

Thus it is no surprise that Grice's maxims do not function normally in schizophrenia. De Decker and Van de Craen (1987) observed that schizophrenic speakers do not follow the maxims when producing speech - thus their answers to questions are off-topic, rambling, and uncooperative. See also Corcoran and Frith (1996) and Tényi et al. (2002). Further experimentation in this area could yield sensitive tests for schizophrenic cognitive impairment.

\subsubsection{Pragmatic disorders distinct from aphasia}

Pragmatic disorders are increasingly being recognized as a set of specific impairments, distinct from aphasia, and found not only in schizophrenia, but also in autism, right-hemisphere damage, and traumatic brain injuries (Martin and McDonald, 2003, Smith and Leinonen, 1992).

Byrne et al. (1998) used clinical pragmatics tests to assess the pragmatic performance of 35 adults diagnosed with schizophrenia; they confirmed that discourse coherence was impaired. Fine (1999) responded by noting a potential circularity: we diagnose schizophrenia on the basis of abnormal discourse, so it should be no surprise that discourse is abnormal in schizophrenia.

\subsection{Lexical access}

\subsubsection{Word-finding difficulties}

Difficulty retrieving lexical items is a common symptom of many mental disorders from brain injury to simple fatigue. In schizophrenia, word-finding is often disordered in a way that goes beyond simple impairment.

Crucially, a common symptom of schizophrenia is word approximation, the use of words that only approximate the intended meaning, such as reflector 'mirror' and exceeding 'protruding from' (McKenna, 1994, p. 14). Word approximation often extends to overuse of existing word formation processes, such as handshoe 'glove,' paperskate 'ballpoint pen' (Andreasen, 1979a), and crusady 'like a crusader' (McKenna, 1994, p. 14). Word approximation gives the hearer the distinct impression that the entire normal vocabulary is not at the speaker's immediate disposal.

Allen et al. (1993) attribute reduced verbal fluency in schizophrenia to impaired lexical retrieval. In several experiments, none of the vocabulary was actually unavailable, but access to it was inefficient. Elvevåg et al. (2002a) and Elvevåg and Storms (2003) 
report further studies in this area and critique the usefulness of some techniques previously used.

\subsubsection{Neologisms}

Sometimes, patients with schizophrenia make up a considerable vocabulary of their own, to express either commonplace ideas, as in "I sort of bawked the whole thing up," (Andreasen, 1979a), or their unique view of the world, as in split-kippered 'simultaneously alive in Lancashire and dead in Yorkshire' (McKenna, 1994, p. 14).

Vetter (1969, pp. 181-193) surveys neologisms and reviews many earlier studies. It appears from his cited examples that neologisms do not violate the phonotactics of the language, though they use uncommon combinations of sounds frequently (which is necessary in order to produce short words that do not exist).

\subsubsection{Stilted speech}

Impaired lexical retrieval appears to be one component of some, but not all, instances of what is called stilted speech in schizophrenia. For example:

(Interpreting "Discretion is the better part of valor":) Pliant rectitude is a trait more appropriate for successful living than hot-headedness, which is either stubborn or crusady. (Harrow and Quinlan, quoted by McKenna, 1994, p. 14)

One cannot help thinking that this patient would not have said pliant rectitude or crusady unless more common words for the same concepts were not accessible.

In other instances, stilted speech apparently involves no lexical impairment, only a failure to control the style (which is a matter of pragmatics), or possibly, as Chen et al. (1996) put it, "excessive syntactic constraint."

A fascinating account of stilted speech "from the inside" is given by Hoffer and Callbeck (1960, p. 144). The narrator was suffering from a schizophrenia-like state induced by LSD and penicillamine and was particularly troubled by an inability to express or understand emotions.

\subsubsection{Intact lexical boundaries}

Using pictures that "morphed" gradually from one shape into another, Elvevåg et al. (2002b) found that the boundaries of applicability of words such as boot, shoe, chair, and stool are unchanged in schizophrenia compared to healthy controls. Accordingly, in this sense, schizophrenic thinking cannot be called "overinclusive," and access to the core meanings of common words is unimpaired.

\subsubsection{Association chaining (glossomania)}

Association chaining may be the only abnormality of schizophrenic speech for which a clear explanation can be offered. It is also found in mania. The speaker is distracted by the sound or meaning of his own words, and leads himself off the topic, sentence by sentence. In essence, it is a form of derailment driven, apparently, by self-monitoring.

Cohen et al. (1974) discovered that, in schizophrenia, semantic glossomania can be triggered by a difficult expressive semantic task. Subjects had to identify a disc by color. With a particularly subtle color distinction, a typical normal description was:

Both are salmon colored. This one, however, has more pink.

Patients with schizophrenia, however, readily went off into glossomania, producing utterances such as:

A fish swims. You call it a salmon. You cook it. You put it in a can. You open the can. You look at it in this color. Salmon fish.

Cohen et al. attribute the glossomania to a failure of editing. In order to describe the color, the speaker must consider many things that are associated with it, and patients with schizophrenia lack the ability to edit out the unwanted alternatives.

\subsubsection{The lexicon as a semantic network}

Connections between words (or word senses) play a vital role in human language. Sentences such as There are pigs in the pen and There is ink in the pen would be much harder to understand if the two different senses of pen were not triggered by semantic priming from pigs and ink respectively.

Studies of the semantic network in schizophrenia go back at least to Kent and Rosanoff (1910). According to a comprehensive review by Minzenberg et al. (2002), in schizophrenia, experimental results involving automatic responses are quite variable; 
some show priming to be impaired, and some, especially in mania-like states, show it to be enhanced. Controlled (conscious) responses, however, are consistently impaired. This indicates that the impairment in semantic access to the lexicon has to do more with utilization of the information than with initial activation of the appropriate node.

Other studies of word recall in schizophrenia generally point toward impaired control of spreading activation (Nestor et al. (1998); Goldberg et al. (1998); Aloia et al. (1998); Kuperberg et al. (1998)). Semantic priming can also be studied through the N400 electroencephalographic response (Fogelson et al., 2004); on the use of this technique in schizophrenia, see Mathalon et al. (2002), Niznikiewicz et al. (1999), (2002), and the studies reviewed by Minzenberg et al. (2002, pp. 713-714).

\subsection{Directions for future research}

Except for semantic priming and discourse cohesion, hardly any aspects of schizophrenic language are well explored. Thus, this entire literature review is practically an agenda for future research. Nonetheless, a few possibilities stand out:

- Tools for all levels of analysis, from phonetics to pragmatics, should be computerized. Not only is the computer faster than a human analyst, it is also free from bias; computer analyses are perfectly reproducible. Recent advances in natural language processing, corpus linguistics, and computer power make analysis much easier than before.

- Current psycholinguistics, advancing rapidly, can shed light on old issues. The work of Pulvermüller (2002) and Jackendoff (2002) has not yet been applied to schizophrenia research.

- The paroxysmal nature of schizophrenic language disturbances should be investigated. Can schizophasia be induced by particular cognitive tasks (Cohen et al., 1974), stimuli, or drugs? What is known about the state of the brain during the paroxysms?

- The heredity of schizophrenic language impairment (DeLisi, 2001) should also be investigated further. It may provide a solid biological basis for differentiating types of schizophrenia.
- Prodromal and subclinical cases of schizophrenia may be detectable by measuring language impairment. This is a public health issue because drug treatment is apparently more effective if started early, and early detection of schizophrenia can save the patient from a wide range of personal misfortunes.

Above all, researchers in this field should do the obvious. Numerous lines of investigation lie open before us and should be pursued.

\section{References}

Abu-Akel, A., 1997. A study of cohesive patterns and dynamic choices utilized by two schizophrenic patients in dialog, preand post-medication. Lang. Speech 40, 331-351.

Abu-Akel, A., 1998. The study of cohesion in schizophrenia: theory and application. Issues Appl. Linguist. 9, 37-60.

Abu-Akel, A., 1999. Impaired theory of mind in schizophrenia. Pragmat. Cogn. 7, 247-282.

Allen, H.A., Liddle, P.F., Frith, C.D., 1993. Negative features, retrieval processes and verbal fluency in schizophrenia. Br. J. Psychiatry 163, 769-775.

Aloia, M.S., Gourovitch, M.L., Missar, D., Pickar, D., Weinberger, D.R., Goldberg, T.E., 1998. Cognitive substrates of thought disorder: II. Specifying a candidate cognitive mechanism. Am. J. Psychiatry 155, 1677-1684. Sequel to Goldberg et al. (1998).

Alpert, M., Rosen, A., Welkowitz, J., Sobin, C., Borod, J., 1989. Vocal acoustic correlates of at affect in schizophrenia: similarity to Parkinson's disease and right hemisphere disease and contrast depression. Br. J. Psychiatry 154, 51-56.

Andreasen, N.C., 1979a. Thought, language, and communication disorders: clinical assessment, definition of terms, and assessment of their reliability. Arch. Gen. Psychiatry 36, 1315-1321.

Andreasen, N.C., 1979b. Thought, language, and communication disorders: diagnostic significance. Arch. Gen. Psychiatry 36, $1325-1330$.

Andreasen, N.C., 1986. Scale for the assessment of thought, language, and communication (TLC). Schizophr. Bull. 12, 473-482.

Andreasen, N.C., Grove, W.M., 1986. Thought, language, and communication in schizophrenia: diagnosis and prognosis. Schizophr. Bull. 12, 348-359.

Bickerton, D., 1990. Language and Species. University of Chicago Press, Chicago.

Byrne, M.E., Crowe, T.A., Griffin, P.S., 1998. Pragmatic language behaviors of adults diagnosed with chronic schizophrenia. Psychol. Rep. 83, 835-846.

Ceccherini-Nelli, A., Crow, T.J., 2003. Disintegration of the components of language as the path to a revision of Bleuler's and Schneider's concepts of schizophrenia. Br. J. Psychiatry $182,233-240$. 
Chaika, E., 1974. A linguist looks at "schizophrenic" language. Brain Lang. 1, 257-276.

Chaika, E.O., 1990. Understanding Psychotic Speech: Beyond Freud and Chomsky. Charles C. Thomas, Springfield, Illinois.

Chaika, E., Lambe, R., 1986. Is schizophrenia a semiotic disorder? Schizophr. Bull. 12, 14-15.

Chapman, J., 1966. The early symptoms of schizophrenia. Br. J. Psychiatry 112, 225-251.

Chen, E.Y.H., Lam, L.C.W., Kan, C.S., Chan, C.K.Y, Kwok, C.L., Nguyen, D.G.H., Chen, R.Y.L., 1996. Language disorganisation in schizophrenia: validation and assessment with a new clinical rating instrument. Hong Kong J. Psychiatry $6(1), 4-13$.

Clemmer, E.J., 1980. Psycholinguistic aspects of pauses and temporal patterns in schizophrenic speech. J. Psycholinguist. Res. 9, 161-185.

Cohen, B.D., Nachmani, G., Rosenberg, S., 1974. Referent communication disturbances in acute schizophrenia. J. Abnorm. Psychol. 83, 1-13.

Corcoran, R., Frith, C.D., 1996. Conversational conduct and the symptoms of schizophrenia. Cogn. Neuropsychiatry 1, 305-318.

Crow, T.J., 1997a. Is schizophrenia the price that Homo sapiens pays for language? Schizophr. Res. 28, 127-141.

Crow, T.J., 1997b. Schizophrenia as failure of hemispheric dominance for language. Trends Neurosci. 20, 339-343.

Crow, T.J., 2000. Schizophrenia as the price that Homo sapiens pays for language: a resolution of the central paradox in the origin of the species. Brain Res. Rev. 31, 118-129.

Cutting, J., 1985. The Psychology of Schizophrenia. Churchill Livingstone, Edinburgh.

De Decker, B., Van de Craen, P., 1987. Towards an interpersonal theory of schizophrenia. In: Wodack, R., Van de Craen, P. (Eds.), Neurotic and Psychotic Language Behaviour. Multilingual Matters, Clevedon, England, pp. 249-265.

DeLisi, L.E., 2001. Speech disorder in schizophrenia: review of the literature and exploration of its relation to the uniquely human capacity for language. Schizophr. Bull. 27, 481-496.

Deese, J., 1978. Thought into speech. Am. Sci. 66, 314-321.

Deese, J., 1984. Thought into Speech: The Psychology of a Language. Prentice-Hall, Englewood Cliffs, N.J.

Docherty, N.M., 1995. Linguistic reference performance in parents of schizophrenic patients. Psychiatry 58, 20-27.

Docherty, N.M., DeRosa, M., Andreasen, N.C., 1996. Communication disturbances in schizophrenia and mania. Arch. Gen. Psychiatry 53, 358-364.

Docherty, N.M., Cohen, A.S., Nienow, T.M., Dizneo, T.J., Dangelmaier, R.E., 2003. Stability of formal thought disorder and referential communication disturbances in schizophrenia. J. Abnorm. Psychology 112, 469-475.

Elvevåg, B., Fisher, J.E., Gurd, J.M., Goldberg, T.E., 2002 a. Semantic clustering in verbal fluency: schizophrenic patients versus control participants. Psychol. Med. 32, 909-917.

Elvevåg, B., Weickert, T., Wechsler, M., Coppola, R., Weinberger, D.R., Goldberg, T.E., 2002b. An investigation of the integrity of semantic boundaries in schizophrenia. Schizophr. Res. 53, $187-198$.
Elvevåg, B., Storms, G., 2003. Scaling and clustering in the study of semantic disruptions in schizophrenia: a re-evaluation. Schizophr. Res. 63, 237-246.

Fine, J., 1999. On the puzzle of language, pragmatics, and schizophrenia. Psychol. Rep. 84, 84-86.

Fogelson, N., Loukas, C., Brown, J., Brown, P., 2004. A common N400 EEG component reflecting contextual integration irrespective of symbolic form. Clin. Neurophysiol. 115, 1349-1358.

Fraser, W.I., King, K.M., Thomas, P., Kendell, R.E., 1986. The diagnosis of schizophrenia by language analysis. Br. J. Psychiatry 148, 275-278.

Freud, S., 1904/1965. Zur psychopathologie des alltagslebens (Translated by Alan Tyson). The psychopathology of everyday life. Norton, New York.

Frith, C.D., 1992. The Cognitive Neuropsychology of Schizophrenia. Psychology Press, Hove, E. Sussex.

Fromkin, V.A. (Ed.), 1973. Speech Errors as Linguistic Evidence. Mouton, The Hague.

Fromkin, V.A., 1975. A linguist looks at "A linguist looks at 'schizophrenic language."”. Brain Lang. 2, 498-503.

Gerson, S.N., Benson, D.F., Frazier, S.H., 1977. Diagnosis: schizophrenia versus posterior aphasia. Am. J. Psychiatry 134, 966-969.

Goldberg, T.E., Aloia, M.S., Gourovitch, M.L., Missar, D., Pickar, D., Weinberger, D.R., 1998. Cognitive substrates of thought disorder: I. The semantic system. Am. J. Psychiatry 155, 1671-1676 (See Aloia et al. (1998) for follow-up).

Goldstein, M.J., 1985. Family factors that antedate the onset of schizophrenia and related disorders: the results of a fifteen-year prospective longitudinal study. Acta Psychiatr. Scand., Suppl. 17 (Suppl. 319), 7-18.

Grice, H.P., 1975. Logic and conversation. In: Cole, P., Morgan, J. (Eds.), Syntax and Semantics, Speech Acts, vol. 3. Academic Press, New York, pp. 41-58.

Harrod, J.B., 1986. Schizophrenia as a semiotic disorder. Schizophr. Bull. 12, 12-13.

Harrow, M., Prather, P., Lanin-Kettering, I., 1986. Is schizophrenia a semiotic disorder? Schizophr. Bull. 12, 15-19.

Head, H., 1926. Aphasia and Kindred Disorders of Speech. Cambridge University Press, Cambridge. 2 vols.

Hoffer, A., Callbeck, M.J., 1960. Drug-induced schizophrenia. J. Ment. Sci. 106, 138-159.

Hoffman, R.E., Hogben, G.L., Smith, H., Calhoun, W.F., 1985. Message disruptions during syntactic processing in schizophrenia. J. Commun. Disord. 18, 183-202.

Hoffman, R.E., Stopek, S., Andreasen, N.C., 1986. A comparative study of manic vs. schizophrenic speech disorganization. Arch. Gen. Psychiatry 43, 831-838.

Jackendoff, R.S., 2002. Foundations of Language: Brain, Meaning, Grammar, Evolution. Oxford University Press, Oxford.

Kent, G.H., Rosanoff, M.D., 1910. A study of association in insanity. Am. J. Insanity 67, 317-390.

King, K., Fraser, W.I., Thomas, P., Kendell, R.E., 1990. Reexamination of the language of psychotic subjects. Br. J. Psychiatry 156, 211-215.

Kleist, K., 1914. Aphasie und Geisteskrankheit. Münch. Med. Wochenschr. 61, 8-12. 
Kuperberg, G.R., McGuire, P.K., David, A.S., 1998. Reduced sensitivity to linguistic context in schizophrenic thought disorder: evidence from on-line monitoring for words in linguistically anonymous sentences. J. Abnorm. Psychology 107, 423-434.

Lecours, A.R., Vanier-Clément, M., 1976. Schizophasia and jargonaphasia. Brain Lang. 3, 516-565.

Levy, R., 1966. The effect of chlorpromazine on sentence structure of schizophrenic patients. Psychopharmacologia 13, 426-432.

Liddle, P.F., Ngan, E.T.C., Caissie, S.L., Anderson, C.M., Bates, A.T., Quested, D.J., White, R., Weg, R., 2002. Thought and language index: an instrument for assessing thought and language in schizophrenia. Br. J. Psychiatry 181, 326-330.

Martin, I., McDonald, S., 2003. Weak coherence, no theory of mind, or executive dysfunction? Solving the puzzle of pragmatic language disorders. Brain Lang. 85, 451-466.

Mathalon, D.H., Faustman, W.O., Ford, J.M., 2002. N400 and automatic semantic processing abnormalities in patients with schizophrenia. Arch. Gen. Psychiatry 59, 641-648.

McGrath, J., 1991. Ordering thoughts on thought disorder. Br. J. Psychiatry 158, 307-316.

McKenna, P.J., 1994. Schizophrenia and Related Syndromes. Oxford University Press, Oxford.

Mellor, C.S., 1970. First rank symptoms of schizophrenia. Br. J. Psychiatry 117, 15-23.

Meringer, R., Mayer, C., 1895. Versprechen und Verlesen: Eine Psychologisch-linguistische Studie. Benjamins, Amsterdam. Reprinted 1978.

Minzenberg, M.J., Ober, B.A., Vinogradov, S., 2002. Semantic priming in schizophrenia: a review and synthesis. J. Int. Neuropsychol. Soc. 8, 699-720.

Morice, R., Ingram, J.C.L., 1982. Language analysis in schizophrenia: diagnostic implications. Aust. N. Z. J. Psychiatry 16, $11-21$.

Morice, R., McNicol, D., 1985. The comprehension and production of complex syntax in schizophrenia. Cortex 21, 567-580.

Morice, R., McNicol, D., 1986. Language changes in schizophrenia: a limited replication. Schizophr. Bull. 12, 239-251.

Nestor, P.G., Akdag, S.J., O’Donnell, B.F., Niznikiewicz, M., Law, S., Shenton, M.E., McCarley, R.W., 1998. Word recall in schizophrenia: a connectionist model. Am. J. Psychiatry 155, $1685-1690$.

Niznikiewicz, M.A., Voglmaier, M., Shenton, M.E., Seidman, L.J., Dickey, C.C., Rhoads, R., Teh, E., McCarley, R.W., 1999. Electrophysiological correlates of language processing in schizotypal personality disorder. Am. J. Psychiatry 156, $1052-1058$

Niznikiewicz, M.A., Shenton, M.E., Voglmaier, M., Nestor, P.G., Dickey, C.C., Frumin, M., Seidman, L.J., Allen, C.G., McCarley, R.W., 2002. Semantic dysfunction in women with schizotypal personality disorder. Am. J. Psychiatry 159, $1767-1774$

Nöth, W., 1976. Textkohärenz und Schizophrenie. Lili: Zeitschrift für Literaturwissenschaft und Linguistik 6.23/24, 175-194.

Oh, T.M., McCarthy, R.A., McKenna, P.J., 2002. Is there a schizophasia? A study applying the single case approach to formal thought disorder in schizophrenia. Neurocase 8 , $233-244$.

Pinard, G., Lecours, A.R., 1983. The language of psychotics and neurotics. In: Ours, A.R., Lhermitte, F., Bryans, B. (Eds.), Aphasiology. Ballière Tindall, London, pp. 313-335.

Pinker, S., 1992. Review of Bickerton (1990). Language 68, $375-382$.

Pulvermüller, F., 2002. The Neuroscience of Language. Cambridge University Press, Cambridge.

Püschel, J., Stassen, H.H., Bomben, G., Scharfetter, C., Hell, D., 1998. Speaking behavior and speech sound characteristics in acute schizophrenia. J. Psychiatr. Res. 32, 89-97.

Rieber, R.W., Vetter, H., 1994. The problem of language and thought in schizophrenia: a review. J. Psycholinguist. Res. 23, $149-195$.

Rochester, S., Martin, J.R., 1979. Crazy Talk: A Study of the Discourse of Schizophrenic Speakers. Plenum, New York.

Rodriguez-Ferrera, S., McCarthy, R.A., McKenna, P.J., 2001. Language in schizophrenia and its relationship to formal thought disorder. Psychol. Med. 31, 197-205.

Schneider, K., 1959. Clinical Psychopathology. Grune \& Stratton, New York. Hamilton, M.W. (Trans.)

Smith, B.R., Leinonen, E., 1992. Clinical Pragmatics: Unravelling the Complexities of Communicative Failure. Chapman \& Hall, London.

Spoerri, T., 1961. Der Ausdruck der gepreßten Sprechstimme (Würgstimme) bei chronischen Schizophrenen. Confin. Psychiatr. 4, 123-132.

Spoerri, T., 1964. Sprachphänomene und Psychose. S. Karger, Basel.

Spoerri, T., 1966. Speaking voice of the schizophrenic patient. Arch. Gen. Psychiatry 14, 581-585.

Stassen, H.H., 1991. Affective state and voice: the specific properties of overtone distributions. Methods Inf. Med. 30, $44-52$.

Stassen, H.H., Albers, M., Püschel, J., Scharfetter, C., Tewesmeier, M., Woggon, B., 1995. Speaking behavior and voice sound characteristics associated with negative schizophrenia. J. Psychiatr. Res. 29, 277-296.

Stein, J., 1993. Vocal alterations in schizophrenic speech. J. Nerv. Ment. Dis. 181, 59-62.

Taylor, M.A., 1999. The Fundamentals of Clinical Neuropsychiatry. Oxford University Press, New York.

Tényi, T., Herold, R., Szili, I.M., Trixler, M., 2002. Schizophrenics show a failure in the decoding of violations of conversational implicatures. Psychopathology 35, 25-27.

Thomas, P., 1997. What can linguistics tell us about thought disorder? In: Muir, J.F.N. (Ed.), Communication and the Mentally Ill Patient: Developmental and Linguistic Approaches to Schizophrenia. Kingsley, London, pp. 30-42.

Thomas, P., Fraser, W., 1994. Linguistics, human communication, and psychiatry. Br. J. Psychiatry 165, 585-592.

Thomas, P., King, K., Fraser, W.I., 1987. Positive and negative symptoms of schizophrenia and linguistic performance. Acta Psychiatr. Scand. 76, 144-151.

Thomas, P., King, K., Fraser, W.I., Kendell, R.E., 1990. Linguistic performance in schizophrenia: a comparison of acute and chronic patients. Br. J. Psychiatry 156, 204-210. 
Vetter, H., 1969. Language Behavior and Psychopathology. Rand McNally, Chicago.

Williams, C.E., Stevens, K.N., 1972. Emotions and speech: some acoustical correlates. J. Acoust. Soc. Am. 52, 1238-1250.

Wróbel, J., 1990. Language and Schizophrenia. Benjamins, Amsterdam. Linguistic and Literary Studies in Eastern Europe, 33.

Wynne, L.C., Singer, M.T., Bartko, J.J., Toohey, M.L., 1977. Schizophrenics and their families: research on parental communica- tion. In: Tanner, J.M. (Ed.), Developments in Psychiatric Research. Hodder \& Stoughton, London, pp. 254-286. (We have been unable to trace a 1975 New York edition of this book that is often cited; it is not in the Library of Congress and we suspect that a mistaken bibliography entry has been passed along). 